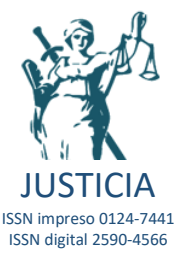

\title{
La nacionalidad como un derecho humano: El caso Satya de Ecuador
}

\author{
Nationality as a human right: The Satya case of \\ Ecuador \\ Sorily Carolina Figuera Vargas
Centro de Investigación y Capacitación Académica "Bartolomé de las Casas", Ecuador \\ sorilyf@yahoo.com \\ Johana Robles Arias \\ Universidad Católica, Ecuador \\ johana-ra17@hotmail.com
}

Recibido: 19 de agosto de 2018 / Aceptado: 14 de octubre de 2018 https://doi.org/10.17081/just.24.35.3387

\section{Resumen}

La nacionalidad es un derecho humano universal consagrado en las principales convenciones internacionales vigentes en el continente americano. Luego que la Corte Constitucional del Ecuador dictó la Sentencia N 184-18-SEP-CC, en fecha 29 de mayo de 2018, relativa al caso Satya, el siguiente análisis resulta relevante en cuanto al estudio de la nacionalidad, su definición, sus principios, su regulación internacional, cuáles han sido algunos de los criterios de la Corte Interamericana de Derechos Humanos en relación con esta figura jurídica y cómo Ecuador regula la nacionalidad en su sistema legal. Finalmente se procederá a la disertación sobre la mencionada sentencia en lo referente a la nacionalidad como derecho humano, su conexión con el derecho a la identidad y el interés suprior de las niñas y niños. Así pues, se desarrollará un método de investigación jurisprudencial para llegar a las conclusiones sobre este debate.

Palabras clave: nacionalidad, identidad, derechos humanos, Corte Constitucional del Ecuador y sistema jurídico ecuatoriano.

\section{Abstract}

Nationality is a universal human right enshrined in the main international conventions in force in the Americas. After the Constitutional Court of Ecuador issued Judgment No. 184-18-SEP-CC, dated May 29,2018 , regarding the Satya case, the following analysis is relevant in terms of the study of nationality, its definition, its principles, its international regulation, which have been some of the criteria of the Inter-American Court of Human Rights in relation to this legal figure, how Ecuador regulates nationality in its legal system. To finally proceed to the dissertation on the aforementioned sentence in relation to nationality as a human right and its connection with the right to identity and the supreme interest of children. Thus, a jurisprudential research method will be developed to reach conclusions on this debate.

Keywords: nationality, identity, human rights, Constitutional Court of Ecuador and Ecuadorian legal system.

\section{Como citar:}

Figuera Vargas, S., \& Robles Arias, J. (2019). La nacionalidad como un derecho humano: El caso Satya de Ecuador. Justicia, 24(35). 41-53. https://doi.org/10.17081/just.24.35.3387 


\section{INTRODUCCIÓN}

No existe unanimidad al momento de definir nacionalidad y en varias ocasiones se confunde con el término de ciudadanía. De manera general, se puede decir que la nacionalidad es el vínculo político, jurídico que une a las personas con el Estado y forma parte de los atributos de la personalidad. Los atributos de la personalidad son inherentes a la persona. Esto implica que ninguna persona puede ser privada de ellos y su pleno ejercicio debe ser garantizado por el Estado. Cabe señalar, además, que las personas naturales y jurídicas comparten todos los atributos excepto el de estado civil que es exclusivo de la persona natural.

En las siguientes páginas se desarrollará un análisis que tiene como fin último responder a las siguientes interrogantes ¿Puede el Estado negar el derecho a la inscripción en el Registro Civil de una niña nacida en su territorio, en donde tiene vigencia el lus soli según su Constitución, negando su derecho a la identidad personal en relación a la obtención de la nacionalidad? ¿Se puede alegar la inexistencia de una legislación que contemple la duplicidad de filiación materna en una inscripción de nacimiento para negar el derecho humano a la nacionalidad?

\subsection{Definición de nacionalidad}

Pascual Estanislao Mancini en un informe presentado en 1851 en la Universidad de Turín y posteriormente en su conferencia ante el Instituto de Derecho Internacional en Ginebra en 1874, propuso con la finalidad de lograr la unificación italiana, un sistema basado en el concepto de la nacionalidad; para este precursor, debían ser las naciones y no los Estados, los factores de la convivencia internacional.

El jurista italiano en su ponencia expresó, qué debía entenderse por nacionalidad, al señalar que

... Y ciertamente el título de derecho se deriva de la inviolable legitimidad del ejercicio de la libertad de cada hombre, o de una asociación de hombres, mientras se mantenga respetuoso hacia la libertad igualmente legítima de los otros hombres. El derecho de nacionalidad, pues, no es más que la misma libertad del individuo, ampliada al común desarrollo del agregado orgánico de individuos que forman las naciones; la nacionalidad no es más que la manifestación colectiva de la libertad, siendo tan santa y divina como la libertad misma. De ahí que en cada nación esta libertad no pueda tener otro límite que aquél donde comienza la violación de esa misma libertad que es obligado respetar para con todas las demás... (Mancini, 1985, p.37).

Ahora bien, en busca de una definición dada por la doctrina, cabe establecer que la nacionalidad es

... un derecho natural o fundamental, que se refiere al vínculo común que une a las distintas personas con un origen común y un territorio $y$ tradiciones compartidas y que los liga normalmente a un determinado Estado y los hace destinatarios de sus normas de Derecho privado. (Otero, 1998, p.451).

Un punto importante que se debe abordar sobre esta temática, sin duda es la distinción entre nacionalidad y ciudadanía. Se puede afirmar que la nacionalidad se relaciona con un sentido de identidad nacional. La identidad nacional no solo se da por el hecho de haber nacido en un determinado país, sino que puede haber casos en los cuales personas que no son 
originarios de ese territorio sientan un lazo de pertenencia con las costumbre y tradiciones de cierta nación a la cual ellos quieren pertenecer.

Por otro lado, la ciudadanía implica el conjunto de derechos y deberes que tiene el ciudadano. Por ejemplo, los derechos políticos. Los términos ciudadanía y nacionalidad se complementan entre sí, pero de ninguna forma son sinónimos.

La nacionalidad suele definirse desde una perspectiva jurídico-política entendiéndose ese término jurídico como el vínculo que une a un sujeto (súbdito) con la organización política denominada Estado. (Fuentes, 2008).

Así pues, desde el enfoque antes señalado, se considera que la nacionalidad es un vínculo jurídico y político que relaciona las personas (y por ficción, ciertas cosas personalizadas), con un Estado, que en consecuencia crea un estatuto que les diferencia de la situación de las demás personas, que, por antagonismo se denominan extranjeros. (Larrea, 2012).

Para Enríquez, la nacionalidad es un vínculo jurídico debido a que involucra aspectos relacionados con normas de carácter legal, como por ejemplo, el servicio militar, aunque no es obligatorio. Luego, la nacionalidad es un vínculo político debido a que establece el ejercicio de ciertos derechos llamados "políticos", como por ejemplo el derecho a ser elegido para ejercer cargos de elección popular, prerrogativa generalmente excluida a los extranjeros. (2017).

Se debe recalcar, que la nacionalidad va mucho más allá de vínculos legales y políticos, otorgando un sentido de pertenencia, debido a que agrupa individuos que se sienten parte de un espacio geográfico y que comparten tradiciones, cosmovisiones, lengua, historia porque son originarios de ese Estado o se sienten identificados con esa Nación que los acoge.

Para determinar los caracteres por los cuales se vincula a un grupo de individuos con una nación específicas, se han utilizado dos concepciones antagónicas, la objetiva y la subjetiva. La primera fundamenta a la comunidad nacional en elementos de hecho determinados por la etnología, entre los que podemos enumerar: el territorio, la lengua, la religión, la raza o la cultura; la segunda, encuadra a la nación en preceptos de orden ideal y espiritual. Esta última concepción estima que la nación deriva de un estado de conciencia, compartido por los integrantes de un grupo específico, que se auto distingue de otros grupos semejantes. (Figuera 2015; Rousseau, 1966).

No obstante lo antes expuesto, autores como Enríquez recomiendan que al hacer referencia a la nacionalidad de una persona, no se cometa el error de pensar en su Nación, sino en el Estado al que pertenece ese sujeto. (2017).

Existen dos causas primordiales que han dado lugar a la existencia de la nacionalidad: la necesidad de establecer el status jurídico de las personas y la movilidad humana. En primer lugar, cuando se establece el estatus jurídico de la persona, se la puede individualizar frente a la comunidad internacional. La nacionalidad da a la persona natural un sentido de pertenencia a un lugar determinado y es un derecho fundamental, que asegura el ejercicio de muchos derechos asociados a ella. (Enríquez, 2017).

Otras de las razones por las cuales se respalda la existencia de la nacionalidad es la movilidad humana. La movilidad humana implica un cambio de lugar de residencia para establecerse en otro lugar de manera temporal o definitiva. Los extranjeros pueden adquirir la nacionalidad por naturalización. Las formas de adquirir la nacionalidad son diferentes en cada estado. Entonces, es obligación de los Estados salvaguardar este derecho humano. Por ejemplo, en el caso de los refugiados que no están protegidos por su propio gobierno, deben ser acogidos por otros Estados y se necesita legislar en base a esta realidad para asegurarles una debida protección internacional. (Enríquez, 2017).

Finalmente, los principios que rigen la nacionalidad que suelen enumerar los autores, son: 
1) Toda persona debe tener una nacionalidad;

2) Toda persona debe tener solo una nacionalidad debido que la nacionalidad se basa en el patriotismo; principio este altamente discutido por la doctrina, haciéndose cada vez más común la regulación de la doble nacionalidad en las legislaciones de los distintos Estados que integran la comunidad internacional;

3) Toda persona puede cambiar de nacionalidad, la renuncia pura y simple de la nacionalidad no basta para perderla;

4) La nacionalidad de origen no debe trasmitirse indefinidamente en el extranjero;

5) La nacionalidad adquirida puede ser revocada. (Enríquez, 2017).

Resulta oportuno ahora, estudiar la nacionalidad como derecho humano en el ámbito internacional.

1.2. La nacionalidad como derecho humano en los sistemas universal e interamericano de protección.

Debe iniciarse este apartado, señalando que el artículo 15 de la Declaración Universal de Derechos Humanos, prevé que

1. Toda persona tiene derecho a una nacionalidad.

2. A nadie se privará arbitrariamente de su nacionalidad ni del derecho a cambiar de nacionalidad. (Declaración Universal de Derechos Humanos, 1948).

Asimismo, el artículo 20 de la Convención Americana sobre Derechos Humanos, establece que

1. Toda persona tiene derecho a una nacionalidad.

2. Toda persona tiene derecho a la nacionalidad del Estado en cuyo territorio nació si no tiene derecho a otra.

3. A nadie se privará arbitrariamente de su nacionalidad ni del derecho a cambiarla. (Convención Americana sobre Derechos Humanos, 1969).

De tal manera, los Estados que integran el sistema universal y el sistema interamericano de derechos humanos deben garantizar las prerrogativas que se derivan de la nacionalidad en los términos de los instrumentos citados. Así pues, se entiende que las personas que están amparadas dentro de esos sistemas de protección tienen derecho a la nacionalidad desde su nacimiento y no existen condiciones para su obtención. En el caso de la naturalización, esta se encuentra regulada por cada Estado como acto soberano. Además, los requisitos son mínimos y en ningún caso discrimina a las personas para conseguirla.

La Corte Interamericana de Derechos Humanos en su Opinión Consultiva OC-4/84 del 19 de enero de 1984, determinó que

La nacionalidad, conforme se acepta mayoritariamente, debe ser considerada como un estado natural del ser humano. Tal estado es no sólo el fundamento mismo de su capacidad política sino también de parte de su capacidad civil. De alli que, no obstante que tradicionalmente se ha aceptado que la determinación y regulación de la nacionalidad son competencia de cada Estado, la evolución cumplida en esta materia nos demuestra que el derecho internacional impone ciertos límites a la discrecionalidad de los Estados y que, en su estado actual, en la 
reglamentación de la nacionalidad no sólo concurren competencias de los Estados sino también las exigencias de la protección integral de los derechos humanos. (CIDH, OC-4/84, 1984).

La Opinión Consultiva OC-4/84 del 19 de enero de 1984, fue presentada por Costa Rica y la $\mathrm{CIDH}$ hizo un análisis sobre la reforma que se pretendía hacer en ese Estado, con la finalidad de modificar algunos aspectos relativos para la adquisición de la nacionalidad. La Corte determinó que había una discriminación en dicho proyecto debido a que se pretendía establecer parámetros diferentes para obtener la nacionalidad por vía de naturalización, dependiendo del género del solicitante. Lo que se pretendía era privilegiar al género masculino. (Rodríguez, 2011).

Sobre el tema en estudio, resulta oportuno destacar como la Corte Interamericana de Derechos Humanos, en el Caso de Personas Dominicanas y Haitianas Expulsadas vs. República Dominicana, de fecha 28 de agosto de 2014, dictaminó que

El Estado debe adoptar, en un plazo razonable, las medidas legislativas, inclusive, si fuera necesario, constitucionales, administrativas y de cualquier otra índole que sean necesarias para regular un procedimiento de inscripción de nacimiento que debe ser accesible y sencillo, de modo de asegurar que todas las personas nacidas en su territorio puedan ser inscritas inmediatamente después de su nacimiento independientemente de su ascendencia u origen y de la situación migratoria de sus padres [...] (CIDH, Serie C No. 282, 2014).

Las autoridades en República Dominicana con el pasar del tiempo han ido adoptando una serie de prácticas, normas y decisiones judiciales dirigidas a desnacionalizar a las personas nacidas en ese país, descendientes de migrantes haitianos. (CIDH, Informe de País República Dominicana, 2016)

Ese proceso de desnacionalización comenzó con la práctica de los funcionarios del registro civil de negarse a registrar el nacimiento de hijos e hijas de migrantes haitianos nacidos en República Dominicana. (CIDH, Informe de País República Dominicana, 2016).

Después, la situación se fue expandiendo y consolidando de forma gradual, por medio de la adopción de normas y decisiones judiciales de los demás poderes del Estado dominicano, especialmente, con la Sentencia 168/13, dictada el 23 de septiembre de 2013 por el Tribunal Constitucional de ese país. Tal situación generó que decenas de miles de personas hayan quedado apátridas en República Dominicana, al no poseer otra nacionalidad. (CIDH, Informe de País República Dominicana, 2016).

Por otra parte, se expondrá como en la séptima conferencia Internacional Americana, Montevideo 1933 sobre nacionalidad, los Estados miembros llegaron a un acuerdo en el cual se dispuso lo siguiente

Artículo 5. - La naturalización confiere la nacionalidad sólo a la persona naturalizada, y la pérdida de la nacionalidad, sea cual fuere la forma en que ocurra, afecta sólo a la persona que la ha perdido.

Artículo 6. - Ni el matrimonio ni su disolución afectan a la nacionalidad de los cónyuges o de sus hijos.

Artículo 7. - La presente Convención no afecta los compromisos contraídos anteriormente por las Altas Partes Contratantes en virtud de acuerdos internacionales (Conferencia Internacional Americana, 1933, arts. 5, 6 y7). 
El artículo 6 mencionado anteriormente, establece que si existe perdida de la nacionalidad esta no afecta a terceras personas. Este reconocimiento es importante debido a que en la antigüedad todos seguían la suerte de un miembro familiar. Además, es importante mencionar que para obtener la nacionalidad por naturalización, los Estados miembros tienen la libertad de regularlo y establecer los requerimientos necesarios para obtener la carta de naturalización, teniendo presente que es un Derecho Humano. La nacionalidad no se concede en base de raza, sexo o condición socio económica, sino que los Estados deben establecer parámetros mínimos.

En este punto es oportuno citar a Arlettaz (2017), quien afirma que No obstante que tradicionalmente se ha aceptado que la regulación de la nacionalidad es una competencia soberana, la evolución histórica muestra que el Derecho Internacional impone ciertos límites a la discrecionalidad de los Estados. Sin embargo, decir que la definición de la nacionalidad no es una simple prerrogativa estatal no es lo mismo que decir que la definición de la nacionalidad no es en absoluto una prerrogativa estatal. Esto último, obviamente, no es correcto. Dentro de los márgenes que el Derecho Internacional impone a los Estados, estos pueden determinar las condiciones de adquisición originaria y derivada de la nacionalidad. Igualmente, y dentro de esos mismos márgenes, los Estados pueden determinar los requisitos para cambiar de nacionalidad y los casos en que la nacionalidad se pierde. (p.188)

Luego de examinar cómo el sistema universal y el sistema interamericano consagran y conciben la nacionalidad como un derecho humano, seguidamente se estudiará la regulación de esta institución en el sistema jurídico ecuatoriano, para luego analizar el Caso Satya desde la perspectiva propuesta en este artículo.

\subsection{La nacionalidad en el sistema jurídico del Ecuador.}

Se debe reforzar la idea que la nacionalidad es necesaria, exclusiva y voluntaria. Con la nacionalidad la persona puede gozar de protección estatal dentro y fuera de su territorio. Así pues, con la nacionalidad, "se origina un estatuto que los distingue de la situación de las demás personas que por contraposición se llaman extranjeros" (Larrea, 2012, p. 98).

En el caso del Ecuador, el derecho a la nacionalidad se encuentra reconocido en el artículo 6 de la Constitución, al establecer que

Todas las ecuatorianas y los ecuatorianos son ciudadanos y gozarán de los derechos establecidos en la Constitución. La nacionalidad ecuatoriana es el vínculo jurídico político de las personas con el Estado, sin perjuicio de su pertenencia a alguna de las nacionalidades indígenas que coexisten en el Ecuador plurinacional. La nacionalidad ecuatoriana se obtendrá por nacimiento o por naturalización y no se perderá por el matrimonio o su disolución, ni por la adquisición de otra nacionalidad (Constitución del Ecuador, 2008, art. 6).

Debe destacarse que, luego de largas batallas políticas, que no excluyeron la violencia substancialmente verbal, los indígenas del Ecuador lograron que el Estado se defina en el artículo 1 de la Constitución como plurinacional. Tal definición consiste en el reconocimiento de la realidad o del hecho de que en el territorio de este país, coexisten con una mayoría 
mestiza, unas trece naciones o nacionalidades indígenas como prefieren autodenominarse. (Trujillo, 2012).

Del artículo 6 de la Constitución del Ecuador, se puede desprender que, la nacionalidad en este país se obtiene de dos formas: por nacimiento o por naturalización. Según el artículo 7 de la misma Carta Magna, en el Ecuador el sistema para determinar la nacionalidad es mixto, consagrando el lus soli (numeral 1) y el lus sanguinis (numeral 2).

Es necesario mencionar el artículo 14 del Código Civil del Ecuador, en el cual se establece que

Los ecuatorianos, aunque residan o se hallen domiciliados en lugar extraño, están sujetos a las leyes de su patria:

10.- En todo lo relativo al estado de las personas y a la capacidad que tienen para ejecutar ciertos actos, con tal que éstos deban verificarse en el Ecuador; $y$,

2o.- En los derechos y obligaciones que nacen de las relaciones de familia, pero sólo respecto de su cónyuge y parientes ecuatorianos. (Código Civil, 2015, art. 14).

El artículo citado actúa como un mecanismo efectivo para que, a los ecuatorianos, se les aplique el derecho de su nacionalidad más allá de sus fronteras, en lo referente al estado de las personas y a su capacidad para ejecutar ciertos actos que deban verificarse en el Ecuador; al igual que, en lo relativo a derechos y obligaciones que nacen de las relaciones de familia, respecto de cónyuges y parientes ecuatorianos. Todo esto siguiendo los postulados de Mancini sobre la nacionalidad.

Doctrinalmente se han enumerado diferentes causas para perder la nacionalidad, como son: por renuncia a la carta de naturalización, por naturalización en otro estado, por matrimonio con un extranjero, por divorcio del cónyuge extranjero, por traición a la Patria; entre otras. Sin embargo, en Ecuador la nacionalidad se pierde únicamente por renuncia expresa a la carta de naturalización (Constitución del Ecuador, 2008, Art. 8 ultimo inciso y Ley Orgánica de Movilidad Humana, 2017, art. 80).

De allí que, la nacionalidad ecuatoriana por nacimiento “...no es susceptible de renuncia, conforme lo establece la Constitución de la República" (Ley Orgánica de Movilidad Humana, 2017, art. 80). Los ciudadanos que renunciaron a su nacionalidad ecuatoriana por nacimiento, antes de la entrada en vigencia de la Constitución de 1998 para naturalizarse en otros países, pueden recuperar la nacionalidad ecuatoriana en un trámite ante el Ministerio de Relaciones Exteriores y Movilidad Humana de este país.

En cuanto a la adquisición de la nacionalidad, el artículo 8 de la Constitución del Ecuador establece quienes son ecuatorianos por naturalización, en los siguientes términos

1. Las que obtengan la carta de naturalización.

2. Las extranjeras menores de edad adoptadas por una ecuatoriana o ecuatoriano, que conservarán la nacionalidad ecuatoriana mientras no expresen voluntad contraria.

3. Las nacidas en el exterior de madre o padre ecuatorianos por naturalización, mientras aquéllas sean menores de edad; conservarán la nacionalidad ecuatoriana si no expresan voluntad contraria.

4. Las que contraigan matrimonio o mantengan unión de hecho con una ecuatoriana o un ecuatoriano, de acuerdo con la ley.

5. Las que obtengan la nacionalidad ecuatoriana por haber prestado servicios relevantes al país con su talento o esfuerzo Individual. (Constitución de la República del Ecuador, 2008, art. 8). 
Por su parte, el artículo 72 de la Ley Orgánica de Movilidad Humana del Ecuador, establece los requisitos para la obtención de la carta de naturalización, los cuales son

1. Haber residido de forma regular y continua al menos tres años en el Ecuador, o haber sido reconocido como apátrida por el Estado ecuatoriano y residir en el país al menos dos años a partir de tal reconocimiento;

2. Tener más de 18 años cumplidos a la fecha de la solicitud;

3. Para las personas menores de 18 años se requerirá el consentimiento de quienes tengan la patria potestad o tutela legal, se escuchará la opinión de los niños, niñas y adolescentes conforme a lo establecido en la ley competente;

4. Partida de nacimiento o prueba supletoria debidamente legalizada y traducida al castellano de ser el caso, excepto en los casos de personas reconocidas por el Ecuador como apátridas;

5. Copia del documento de identidad o copia del pasaporte vigente, debidamente legalizado;

6. Conocer los símbolos patrios;

7. Exponer en una entrevista los motivos por lo que desea adquirir la nacionalidad ecuatoriana; $y$

8. Demostrar medios lícitos de vida en el país, salvo el caso de menores de 18 años o personas con discapacidad que dependan económicamente de un tercero. (Ley Orgánica de Movilidad Humana, 2017, art. 72).

A manera de recapitulación se puede decir que en este artículo solamente se ha analizado el derecho a la nacionalidad desde el enfoque de las personas naturales. Además, se establecieron las razones por las cuales la nacionalidad es de vital importancia para salvaguardar derechos que se derivan de la dignidad humana.

Además, se expuso el contenido de los instrumentos internacionales vigentes en los sistemas universal e interamericano de protección, que conciben a la nacionalidad como un derecho inherente al ser humano. Por último, se hizo un análisis de la normativa interna del Ecuador con respecto a la nacionalidad, para determinar si la misma se adecua a los principios generales de derecho y está acorde a los estándares internacionales estudiados.

\section{El caso Satya y el derecho humano a la nacionalidad en el Ecuador}

El 8 de diciembre de 2011 nació Satya en Malchinguí, una parroquia de la provincia de Pichincha en la sierra norte de Ecuador. Esta niña fue concebida mediante inseminación artificial. Sus madres Helen Bicknell y Nicola Rothon, ambas de nacionalidad inglesa, son una pareja formal según unión civil celebrada el 25 de Septiembre de 2010 en el Reino Unido y, que luego, fue reconocida como unión de hecho ante el Notario Público Vigésimo Octavo del Cantón Quito, de 24 de Noviembre 2011. Es el caso, que diecinueve días después del nacimiento de Satya, sus progenitoras asistieron al Registro Civil en Ecuador para inscribirla, pero recibieron una negativa.

En una resolución tomada el 10 de enero de 2012, el Registro Civil alegó que en pro de precautelar la seguridad jurídica de la filiación paterna y como la legislación ecuatoriana no contemplaba la duplicidad de filiación materna en una inscripción de nacimiento, no era procedente inscribir el nacimiento de la menor Satya Amani en los términos que se solicitaban; 
es decir, que figurarán como progenitoras ambas madres, con sus respectivos apellidos. (Andes, 2018).

Durante el desarrollo del proceso en Ecuador, la niña Satya fue reconocida en el Reino Unido como hija de la pareja de mujeres y se le otorgó el pasaporte británico a la menor, quien residía en el país suramericano como extranjera, con una visa de amparo expedida por la Cancillería ecuatoriana. (Rodríguez, 2017).

Fue así que, la Defensoría del Pueblo presentó en Ecuador una acción de protección el 8 de marzo de 2012, alegando que se habían negado los derechos de la menor. En la audiencia llevada a cabo el 4 de mayo de 2012, el argumento del Registro fue que ambas mujeres y su hija no eran una familia porque ellas no estaban casadas. De igual forma, fundamentaron su decisión en que las progenitoras no eran ciudadanas ecuatorianas. La solución que les daban a las solicitantes, consistía en que la madre biológica, es decir Nicola, quien se había sometido a una fertilización in vitro, inscribiera a la niña con sus dos apellidos como madre soltera. (Andes, 2018).

Luego, la sentencia que conoció de este caso en segunda instancia, fue dictada el 09 de agosto de 2012, por la Tercera Sala de Garantías Penales de la Corte Provincial de Justicia de Pichincha y negó las pretensiones de las madres, que estaban representadas por la Defensoría del Pueblo del Ecuador. Luego, la Corte Constitucional del Ecuador admitió a trámite la acción extraordinaria de protección $N^{\circ}$ 1692-12-EP, el 30 de septiembre de 2014. Los actores alegaban que la sentencia impugnada violó el derecho a la tutela judicial efectiva, previsto en el artículo 75 de la Constitución del Ecuador y el derecho al debido proceso, consagrado en el artículo 76, numeral 7, literal 1 de la misma Carta Magna.

El 29 de mayo de 2018 la Corte Constitucional de Ecuador dictó la Sentencia N 184-18-SEPCC, con criterios que, indudablemente, significaron una revolución jurídica frente a los conceptos preestablecidos en el sistema jurídico de este país. La decisión se pronunció sobres los derechos de las familias diversas, sobre la filiación, sobre la reproducción asistida y, sobre el tema objeto de este artículo, la identidad personal en relación a la obtención de la nacionalidad.

Es así como, la Sentencia en estudio determinó que la identidad se encuentra entrañablemente relacionada al registro y obtención de una nacionalidad, que permite a las personas, especialmente niños y niñas, lograr la individualización y protección jurídica de sus derechos. Dice el fallo que, los accionantes alegaron una afectación al derecho a la identidad de Satya Amani, pues al negársele su inscripción, se verificó una situación de vulnerabilidad, debido a que la niña no pudo ejercer de forma plena sus derechos reconocidos en la Constitución, esencialmente a tener una la nacionalidad. (Corte Constitucional del Ecuador, $\mathrm{N}^{\circ}$ 184-18-SEP-CC, 2018). En este caso, se le negó a la niña Satya el derecho a obtener la nacionalidad por lus Soli según lo consagra el artículo 7, numeral 1 de la Carta Magna ecuatoriana.

Señala la Sentencia citada, que el derecho a poseer una nacionalidad es fundamental en lo relativo a la protección del interés superior del niño, ya que la nacionalidad es el cimiento de la personalidad jurídica, capacidad política y civil de las personas, sobre la cual dispone su existencia jurídica y el goce de su protección, en cuanto a las facultades inherentes a la dignidad humana y sobre los derechos que son propios de las niñas y niños, que se encuentren en especial condición de vulnerabilidad. (Corte Constitucional del Ecuador, $\mathrm{N}^{\circ} 184-18-\mathrm{SEP}-\mathrm{CC}$, 2018).

La Sentencia en estudio en cuanto a la filiación, hizo énfasis en la interpretación del artículo 69, numeral 7 de la Constitución del Ecuador, que prevé

Art. 69.- Para proteger los derechos de las personas integrantes de la familia: 
7. No se exigirá declaración sobre la calidad de la filiación en el momento de la inscripción del nacimiento, y ningún documento de identidad hará referencia a ella. (Constitución de la República del Ecuador, 2008, art. 69.7).

\begin{abstract}
Así pues, el fallo en análisis estableció que al leer de forma exhaustiva las normas constitucionales referidas al derecho a la familia e identidad de niños, niñas y adolescentes, las parejas del mismo sexo que tengan hijos e hijas biológicas tienen la prorrogativa a inscribirlos bajo los nombres de su identidad familiar, ya que el Ecuador se encuentra obligado a no exigir la calidad de la filiación al momento de registro de las personas recién nacidas, en la medida que estas tienen el derecho a que su identidad individual, de igual forma, responda a la identidad familiar a la que pertenecen, lo cual incluye a una familia LGBTI. Entonces, al no existir prohibición expresa de la identificación familiar de los hijos e hijas de las familias LGBTI, el Estado ecuatoriano no tiene fundamento jurídico para no reconocer este derecho. (Corte Constitucional del Ecuador, $\mathrm{N}^{\circ}$ 184-18-SEP-CC, 2018).
\end{abstract}

Para la Corte Constitucional del Ecuador, un punto importante que debe ser evaluado en este caso, gira entorno al vínculo filial conformado entre los padres y madres para con sus hijos, aspecto que debe garantizarse "desde la diversidad de núcleos familiares existentes, en consideración al goce en condiciones de lgualdad que poseen las uniones de hecho y el especial reconocimiento que la Constitución consagra hacia las familias en sus diversos tipos". (Corte Constitucional del Ecuador, N 184-18-SEP-CC, 2018).

Desde la perspectiva anterior, la misma Corte dictaminó, que para la familia de las señoras Nicola y Helen el empleo de técnicas de reproducción asistida les dio la oportunidad de ejercer su maternidad y fortalecer su núcleo familiar. Recalcando la Sentencia, que en el caso en cuestión, la familia homoparental integrada por dos mujeres, manifestó la intención mutua de procreación, decisión que surgió de la pareja, creando lazos comunes y afectivos que después se expresarían íntimamente en su relación con Satya. (Corte Constitucional del Ecuador, Nº 184-18-SEP-CC, 2018).

En definitiva, la Corte Constitucional del Ecuador decidió en la Sentencia N 184-18-SEP-CC, que la Dirección General de Registro Civil, Identificación y Cedulación, debía proceder de manera inmediata, a la inscripción como ecuatoriana de la niña Satya Amani Bicknell Rothon, reconociendo su filiación como hija de Helen Louise Bicknell y de Nicola Susan Rothon. (Corte Constitucional del Ecuador, N 184-18-SEP-CC, 2018).

El 16 de agosto de 2018, finalmente, Helen Bicknell y Nicola Rothon inscribieron a su hija Satya y a su hermano Arundel, en el Registro Civil del Ecuador. Para recibir las cédulas de los niños con sus nombres, respectivos apellidos maternos y nacionalidades, las dos madres pasaron seis años de trámites, demandas y contra-demandas antes de materializar un sueño, que sus hijos tengan una identidad. (El Telégrafo, 2018).

\title{
II. CONCLUSIONES
}

La Constitución del Ecuador de 2008 es progresista al establecer una serie de derechos de vanguardia, como por ejemplo al determinar la existencia del Sumak Kawsay y establecer la naturaleza como sujeto de derecho. Se puede observar como el artículo 7.1 de ese Texto Constitucional prevé la nacionalidad por nacimiento, desde la perspectiva del lus soli, el artículo 44 establece el interés superior de niñas, niños y adolescentes, así como, el artículo 67 reconoce la familia en sus diversos tipos.

No obstante, si una lección ha dejado el caso Satya en el sistema jurídico ecuatoriano, podría ser, que de nada sirve reconocer los derechos humanos, económicos, sociales, culturales, etc., 
de la manera más avanzada, si las instituciones del Estado y los funcionarios públicos no tienen la formación o el interés para aplicarlos.

A Satya Amani se le vulneró el derecho humano a la identidad personal en relación a la obtención de la nacionalidad. Esta niña nació en el Ecuador, tenía el derecho a ser ecuatoriana por lus solis. Sin embargo, los funcionarios del Registro Civil, Identificación y Cedulación violaron los derechos de Satya, alegando inverosímilmente, que la legislación de este país no contemplaba la duplicidad de filiación materna en una inscripción de nacimiento, dándole la opción retrograda, a que la madre biológica inscribiera a la niña con sus dos apellidos, quedando registrada como madre soltera.

La Sentencia $\mathrm{N}^{\circ}$ 184-18-SEP-CC de la Corte Constitucional del Ecuador es un avance significativo, acorde a las tendencias jurídicas de avanzada, que resguardan los derechos humanos internacionalmente reconocidos, en su amplia dimensión. El fallo citado está en la línea, por ejemplo, de la Opinión Consultiva OC-24/17, solicitada por la República de Costa Rica, sobre la identidad de género, e igualdad y no discriminación a parejas del mismo sexo, que fue emitida por la Corte Interamericana de Derechos Humanos en fecha 24 de noviembre de 2017.

Las autoras de este artículo están convencidas que la sentencia de la Corte Constitucional del Ecuador, en relación de caso Satya, apenas representa el primero de muchos fallos que interpretarán la verdadera dimensión y alcance de la Constitución de 2008.

\section{REFERENCIAS}

Andes. (2018). La historia de Satya, la niña inglesa que nació en Malchinguí. Recuperado el 3 de junio de 2018, de https://www.andes.info.ec/es/noticias/ sociedad/17/satyanacio-en-malchingui

Arlettaz, F. (2017). Entre potestad soberana y derecho humano: la nacionalidad en el sistema americano. Revista de Derecho (Valdivia), 30(1). Recuperado el 3 de junio de 2018, de https://dx. doi.org/10.4067/S0718-09502017000100008

CIDH. (2016). Desnacionalización y Apatridia en República Dominicana. Informe de País República Dominicana. Recuperado el 30 de mayo de 2018, de http://www.oas.org/es/cidh/multimedia/2016/RepublicaDominicana/republicadominicana.html

Del Rosario, M. (2011). El Derecho a la Nacionalidad. Revista Internacional de Derechos Humanos. Recuperado el 15 de junio de 2018, de http://www. cladh.org/wpcontent/uploads/2012/07/a1-n1-2011-art04.pdf

EL Telégrafo. (2018). Satya y Arundel fueron inscritos en el Registro Civil. Recuperado el 16 de agosto de 2018, de https://www.eltelegrafo.com.ec/noticias/sociedad/6/satyaarundel-registro-civil

Enríquez, J. (2017). La Nacionalidad en el Ordenamiento Constitucional Ecuatoriano. Quito: Editorial Jurídica del Ecuador.

Figuera, S. (2015). Jurisdicción Especial Indígena en Latinoamérica. Una referencia específica al sistema jurídico colombiano. Barranquilla: Universidad del Norte y Grupo Editorial Ibáñez. 
Fuentes, D. (2008). Derecho internacional: nacionalidad y protección de la persona en el extranjero. Ciudad de México: Editorial Miguel Ángel Porrúa.

Larrea, J. (2012). Manual de Derecho Internacional Privado Ecuatoriano (Comentarios y actualizaciones por: Dr. Luís Nárvaez Rivadeneira). Quito: Corporación de Estudios y Publicaciones (CEP).

Mancini, P. (1985). Sobre la Nacionalidad. Edición Pérez, A. Traducción Carrera, M.Madrid: Editorial Tecnos, S.A

Otero, M. (1988). La nacionalidad como derecho fundamental. En: Anuario de filosofía del derecho. Recuperado el 15 de junio de 2018, de https://www.boe.es/ publicaciones/anuarios_derecho/anuario. php?id=F_1988_ANUARIO_ de_filosof\%cda_del_derecho

Rodríguez, A. (2017). Satya y su familia diversa. El Telefrafo. Recuperado el 3 de junio de 2018, de https://www.eltelegrafo.com.ec/noticias/702/51/satya-y-su-familiadiversa

Rousseau, C. (1966). Derecho Internacional Público. 3aㅡ ed. Barcelona: Ediciones Ariel.

Trujillo, J. (2012). Plurinacionalidad y Constitución. En: Justicia indígena, plurinacionalidad e interculturalidad en Ecuador. Boaventura de Sousa Santos y Agustín Grijalva Jiménez, editores. Quito: Fundación Rosa Luxemburg y AbyaYala. 


\section{Sorily Carolina Figuera Vargas}

Doctora por la Universidad de Salamanca.

\section{Johana Robles Arias}

Abogada por la Pontificia Universidad Católica del Ecuador. Correo electrónico: johana-ra17@hotmail.com 